mum of $7 \times 10^{-29} \mathrm{~cm} .^{2}$ at $8 \times 10^{9} \mathrm{eV}$. and afterwards falls slowly to zero. This corresponds to a mean free path of not less than 40 metres in lead.

Neglecting damping, the annihilation of nucleon pairs would, in the Dirac approximation, have the same probability for occurrence as the production, apart from a simple factor arising from the different density functions of the final states, and thus the anti-nucleons on being produced would be immediately annihilated. That this is not so is shown by the further application of the radiation damping theory. It is found that the probability that a highenergy negative proton will be annihilated into mesons on passing through lead is less than 20 per cent, and that on being brought to rest the negative proton is annihilated with emission of light quanta with a mean life-time of about $10^{-4}$ sec.

Thus, although the negative proton has not yet been observed, the above figures lead to the estimation that for every 1,000 cosmic ray particles observed at sealevel about $0 \cdot 6$ should be negative protons. Williams found that of two thousand particles observed, eight were protons, so that it is to be expected that of the number of detectable protons about 10 per cent are negative protons. It is suggested that experiments on showers of two particles, similar to those of J. G. Wilson (Nature, 142, 73; 1938) but with ten times the number of photographs, be performed in order to determine the charge on the particles and to verify the theoretical results.

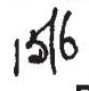

\section{POPULATION POLICY FOR GREAT BRITAIN}

A SERIES of broadgheptyisstied by Political and Economje Plannindefuring the last few months are of consid rablaringest in relation to the proposed nationa healt serdee in Great Britain. The first of ther "Vital Statistics" (No. 241), is concerned with the probable population trends. It points out that althdugh there is scope for further reductions in total mortality, their effect on population growth could only be small compared with last century, when the rapid increase in population was entirely due to the reduction of mortality. Lower fertility within marriage is the main reason why the population has failed to replace itself for the last twenty-four years, and in the long run the declining trend can only be checked by increasing the average number of children per married couple. There are, however, clear signs that it is the deliberate limitation of families by methods of birth control which is mainly responsible for the present decline in fertility. Analysing various possible trends, Planning concludes that in no circumstances would it be realistic to expect an expansion of population in England and Wales comparable to that of the last century. The most that can be expected in the long run is a small increase, and this can only be achieved by reversing present trends.

In broadsheet No. 242, "Retreat from Parenthood", Planning examines the nature of the human impulses and attitudes responsible for this decline in population, and endeavours to set the most important of these factors in their correct historical perspective. Although there is evidence in all ages of some desire to avoid excessive fertility, there does not appear to have been in Europe any widespread desire severely to limit the size of families until the transformation of life by the industrial revolution was far advanced. Thereafter the growth of financial penalties on parenthood as well as the state of public opinion encouraged the small family pattern. Children to-day are the cause of relative rather than absolute poverty, and limitation of the family is an obvious economy of energy as well as of money. The new awareness of insecurity was a further adverse factor, and the neo-Malthusian movement diffused the idea of family limitation far more widely than it succeeded in spreading actual knowledge of contraception. Again, the enjoyment of leisure, like the attainment of security, is apt to conflict with rearing a family, and the growth of sex equality and sexual knowledge have tended to reduce children from an integral part of the happy marriage to a welcome but not indispensable addition to it, if circumstances make a family appear worth while without too much sacrifice.

The broadsheet concludes by pointing out that the new freedom of parenthood in advanced societies marks the end of the epoch of automatic replacement of human numbers, and the institution of voluntary parenthood obliges society to adopt a population policy. Such a policy must take into account prevailing attitudes to marriage and parenthood, and seek to modify them in socially desirable directions. Simultaneously, it must recognize all the disabilities and obstacles to parenthood, and take action to abate or remove them.

One such line of action is discussed in a subsequent major broadsheet (No. 244. "A Complete Maternity Service"), in which the present condition of maternity services in Great Britain is outlined and the main deficiencies are indicated. Further, a full maternity service is outlined and the proper place of the midwife, the health visitor, the general practitioner, the clinic officer and the hospital are discussed and the functions which the health centre can perform in uniting these individuals in a team. The main, and much the most important, emphasis is laid in Planning on team-work and continuity of attention. The second point made in the broadsheet is the development of a more uniform service so that without rigid rules applicable through the whole of Britain for every detail of maternity care, the essential services should be readily available to the woman in a country district as well as to the town dweller and to all income groups. Thirdly, the need of simplifying the administrative structure behind maternity services is stressed. If the target is estab. lished and each move is made with that target clearly in view, the achievement of a really marked improvement should not be so difficult as it appears at present, when each section of the services concerned is apt to over-emphasize its importance. Lastly, there is the need for public education. First-rate administra. tion and first-rate services could founder completely on the rock of ignorance or prejudice; the essential facts of the situation must be known and understood by the public for whose comfort and health maternity services are designed

These three broadsheets belong to a series to be embodied in the PEP report on population policies, but the group responsible for this study has found itself unable to deal with the subject satisfactorily without entering on a wider and more difficult inquiry. Population policy must be seen in the context of a democratic society, and belief in the future of society, education in parenthood, and a higher valuation of parenthood by society are three vital factors making for a sound population policy. 